\title{
Effect of norepinephrine and isoprenaline on the airway resistance of patients with chronic bronchial obstruction
}

\author{
NOÉ Z A MEL, EDUARDOZ. FARACO, AND FLAVIO M. DE \\ F R E I T A S
}

\author{
From the Cardio-pulmonary Laboratory, Department of Clinical Therapeutics, Porto Alegre Medical \\ School, University of Rio Grande do Sul, Brazil
}

The combination of isoprenaline with phenylephrine was recently suggested to have a more marked bronchodilator action in patients with bronchial obstruction than isoprenaline alone. This increased action has been attributed to the vasoconstrictive properties of phenylephrine, which may cause mucosal decongestion. The addition of this effect to the bronchial muscle relaxation elicited by isoprenaline would allow a greater increase of the internal diameter of the bronchi (Cohen, 1962 ; Kallós and Kallós-Deffner, 1964 ; Cohen and Hale, 1965).

Since norepinephrine is one of the most powerful vasoconstrictive substances presently available, the appraisal of its value as a bronchodilator would have both physiopathological and therapeutic implications. There are no references in the medical literature to the use of aerosols containing norepinephrine. This study was therefore undertaken in order to evaluate the effects of norepinephrine before and after the administration of isoprenaline on the airway resistance of patients with chronic bronchial obstruction.

\section{MATERIAL AND METHODS}

Twenty patients (16 male and four female) aged 11 to 66 years (average age 44 years) were studied. Ten patients were diagnosed as having chronic bronchitis and 10 as having asthma, according to the criteria defined by the Ciba Guest Symposium (1959). The diagnosis of gross widespread pulmonary emphysema was made in five patients with chronic bronchitis and in five with asthma. This diagnosis was based on the radiographic examination of the lungs and in accordance with the criteria of Simon and Galbraith (1953). One patient with a long history of chronic bronchitis had recently developed clinical and radiological signs suggesting bronchiectasis. Two patients had had pulmonary tuberculosis; one had radiological signs of fibrous scarring in both upper lobes and the other had calcified foci in the right upper lobe. In both, symptoms of chronic bronchitis had preceded the onset of pulmonary tuberculosis.

None of the patients had received corticosteroids for a period of at least 30 days before the test, and none had received bronchodilators for at least $\mathbf{2 4}$ hours. A Vaponefrin nebulizer ${ }^{1}$ connected to a regulating flow valve of an air cylinder was used for the administration of the aerosols. The valve was set to deliver a flow of $6 \mathrm{l}$./minute. All patients were exposed to doses of $10 \mathrm{mg}$. isoprenaline $(5 \mathrm{mg} . / \mathrm{ml}$.) and $2 \mathrm{mg}$. norepinephrine $(1 \mathrm{mg} . / \mathrm{ml}$.$) . Each exposure lasted approxi-$ mately 10 minutes. The airway resistance and thoracic gas volume were measured by means of a 600-1. body plethysmograph by the method of DuBois, Botelho, and Comroe (1956). The loops were recorded by a cathode-ray photographic recording system ${ }^{2}$. At least six loops were selected to obtain the mean value of each determination. The patients panted at a frequency of approximately 2 cycles/second and the airway resistance was measured at flow rates of 0.51 ./ second.

A control measurement was obtained in every patient. Then one of the drugs was administered, and the determination of the airway resistance and thoracic gas volume was repeated. As soon as a convenient number of loops had been photographed, the second drug was given and a third determination was carried out. Since a random order in the administration of the drugs had been observed on the first day, the same procedure was repeated the following day, but the drugs were used in reverse order.

An interval of approximately five minutes was allowed to elapse between the end of each exposure of the patient to the aerosol and the beginning of the determination of the airway resistance and thoracic gas volume. Meanwhile the patient had been sitting inside the body plethysmograph in order to achieve an appropriate warming up of the air in the box and its sufficient saturation with water vapour. The same was done before the control measurement. Each complete

1The Vaponefrin Co. Dist., Edison, New Jersey, U.S.A.

2DR-8 Research Recorder, Electronics for Medicine Inc., White Plains, New York, U.S.A. 


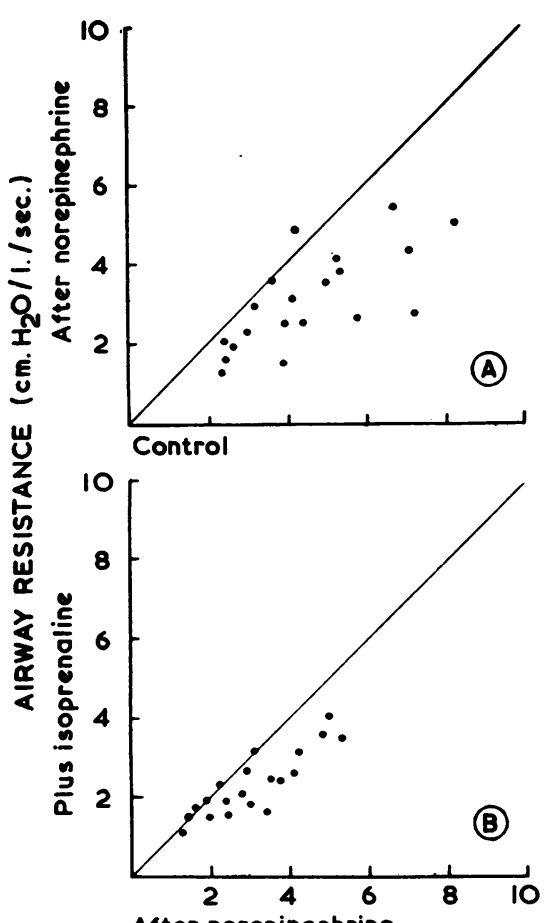

After norepinephrine
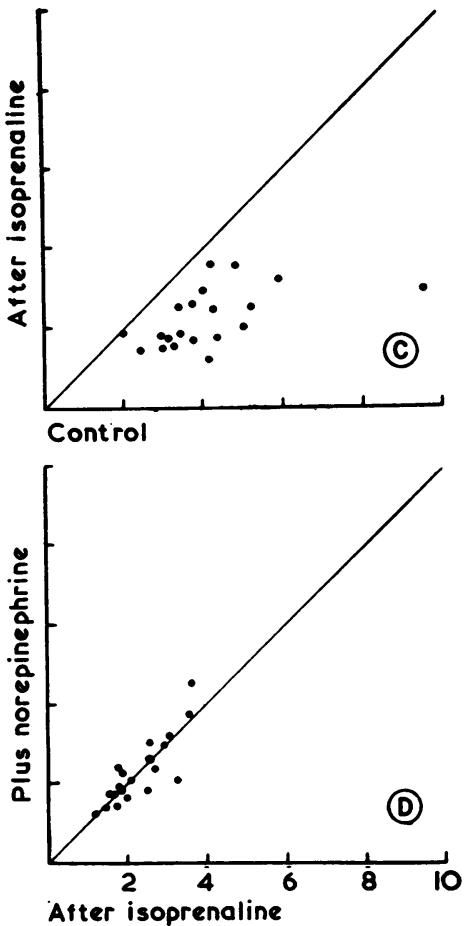

FIG. 1. Behaviour of airway resistance during control and test periods (see text).

AIRWAY RESISTANCE $\left(\mathrm{cm} . \mathrm{H}_{2} \mathrm{O} / \mathrm{I} . / \mathrm{sec}\right.$.)

FIG. 2. Behaviour of thoracic gas volume during control and test periods (see text).
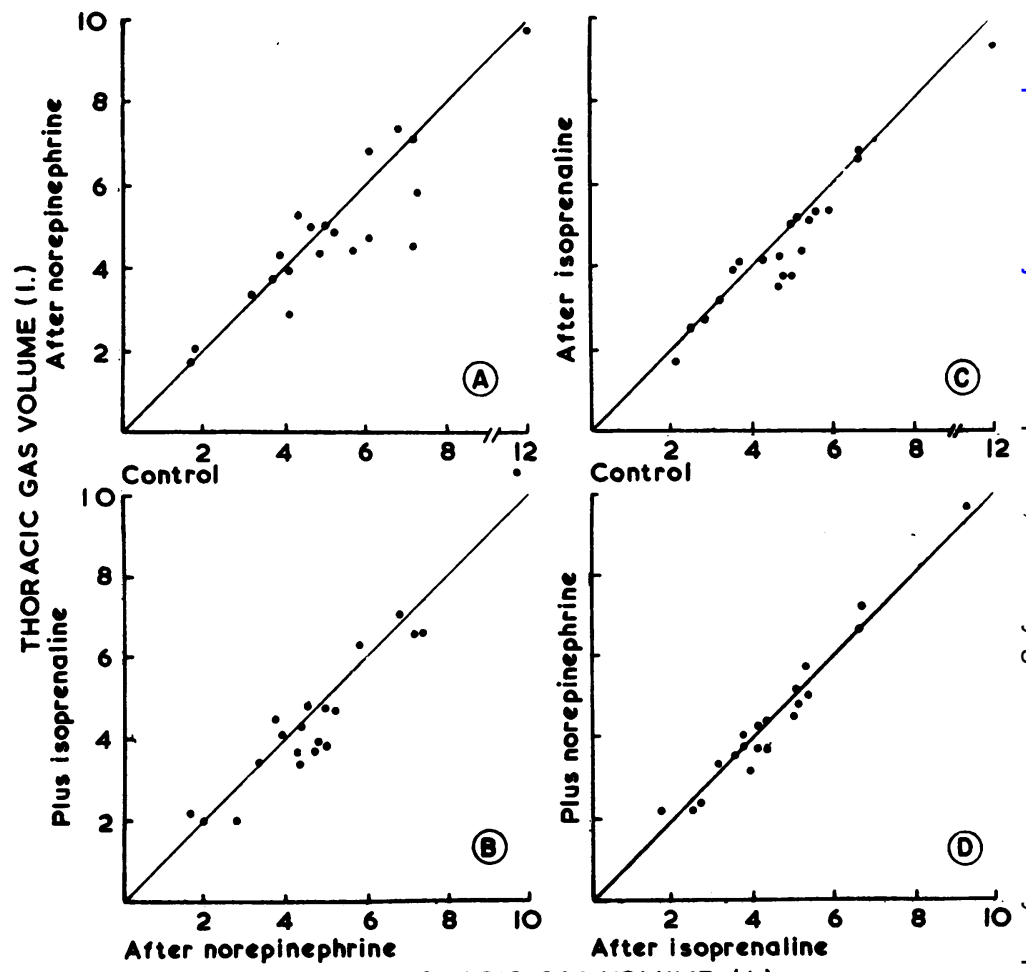

(c)

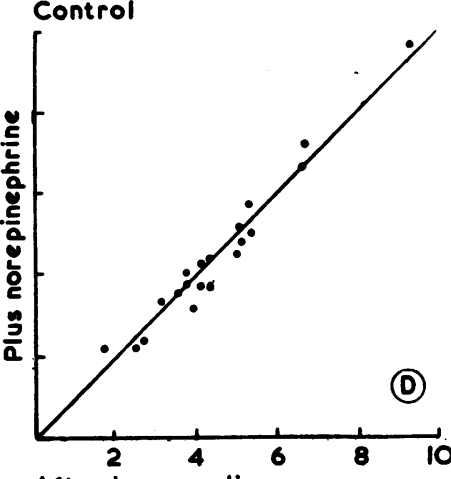

After isoprenaline 
determination of airway resistance and thoracic gas volume consumed an additional five-minute period.

Student's t-test was used in the statistical analysis. The data obtained were arranged according to the 'paired technique', since each patient served as his own control.

\section{RESULTS}

Results for airway resistance and thoracic gas volume are summarized in Table $I$ and arranged graphically in Figures 1 and 2 .

\section{T A B L E I}

EFFECTS OF NOREPINEPHRINE AND ISOPRENALINE ON AIRWAY RESISTANCE AND THORACIC GAS VOLUME

\begin{tabular}{c|c|c|c}
\hline Period of Study & $\begin{array}{c}\text { Mean } \\
\pm \text { S.D. }\end{array}$ & $\begin{array}{c}\text { Mean } \\
\text { Difference } \\
\pm \text { S.E.M. }\end{array}$ & P \\
\hline
\end{tabular}

Airway Resistance (cm. $\mathrm{H}_{2} \mathrm{O}$, 1. $\mathrm{sec}$.)

\begin{tabular}{|c|c|c|c|}
\hline \multirow{2}{*}{$\begin{array}{l}\text { Control } \\
\text { After } \\
\text { norepinephrine } \\
\text { Plus } \\
\text { isoprenaline .. }\end{array}$} & \multirow{2}{*}{$\begin{array}{l}4 \cdot 50 \pm 1 \cdot 70 \\
3 \cdot 03 \pm 1 \cdot 17 \\
2 \cdot 36 \pm 0 \cdot 78\end{array}$} & $1.47 \pm 0.29$ & $<0.001$ \\
\hline & & $0.67 \pm 0.14$ & $<0.001$ \\
\hline \multirow{2}{*}{$\begin{array}{l}\text { Control } \\
\text { After } \\
\text { isoprenaline ... } \\
\text { Plus } \\
\quad \text { norepinephrine }\end{array}$} & \multirow{2}{*}{$\begin{array}{l}4 \cdot 12 \pm 1 \cdot 57 \\
2 \cdot 24 \pm 0 \cdot 70 \\
2 \cdot 30 \pm 0 \cdot 80\end{array}$} & $1 \cdot 88 \pm 0.32$ & $<0.001$ \\
\hline & & $0.06 \pm 0.09$ & Not s \\
\hline
\end{tabular}

Thoracic Gas Volume (1.)

\begin{tabular}{|c|c|c|c|}
\hline \multirow{2}{*}{$\begin{array}{l}\text { Control } \\
\text { After } \\
\text { norepinephrine } \\
\text { Plus } \\
\text { isoprenaline .. }\end{array}$} & \multirow{2}{*}{$\begin{array}{l}5 \cdot 24 \pm 2 \cdot 22 \\
4 \cdot 83 \pm 1 \cdot 84 \\
4 \cdot 63 \pm 1 \cdot 98 \\
\end{array}$} & $0.41 \pm 0.22$ & Not significant \\
\hline & & $0.20 \pm 0.14$ & Not significant \\
\hline \multirow{2}{*}{$\begin{array}{l}\text { Control } \\
\text { After } \\
\text { isoprenaline ... } \\
\begin{array}{l}\text { Plus } \\
\text { norepinephrine }\end{array}\end{array}$} & \multirow{2}{*}{$\begin{array}{l}4.93 \pm 2.03 \\
4.50 \pm 1 \cdot 65 \\
4.45 \pm 1.65\end{array}$} & $0.43 \pm 0.16$ & $<0.02$ \\
\hline & & $0.05 \pm 0.08$ & Not significant \\
\hline
\end{tabular}

AIRWAY RESISTANCE When norepinephrine was used in the first place, there was a significant decrease $(P<0.001)$ of the airway resistance in comparison with the control values (Table I, Fig. 1A). The same occurred ( $P<0.001)$ with isoprenaline (Table I, Fig. 1C). Results for airway resistance obtained when norepinephrine was administered after isoprenaline were not significantly different from those obtained with isoprenaline alone (Table I, Fig. ID). However, when this last drug was given after norepinephrine there was a further significant decrease $(P<0.001)$ of the airway resistance (Table I, Fig. 1B).

THORACIC GAS VOLUME The administration of norepinephrine either before or after isoprenaline did not change appreciably the thoracic gas volume (Table I, Figs $2 \mathrm{~A}$ and $2 \mathrm{D}$ ). A slight but significant decrease $(P<0.02)$ of the thoracic gas volume was noted when isoprenaline was used as the first drug (Table I, Fig. 2C). Changes were not significant when isoprenaline was used after norepinephrine (Table I, Fig. 2B).

\section{DISCUSSION}

The relation between airway resistance and thoracic gas volume has been well established; the airway resistance decreases when the lung volume increases (Briscoe and DuBois, 1958). It was also demonstrated by Butler, Caro, Alcala, and DuBois (1960) that this relationship is determined by the elastic properties of the lung. These authors found that, in patients with asthma and in patients with pulmonary emphysema, the change in airway resistance per unit change in lung volume was less than normal. They also found that the curve of airway resistance versus lung volume could be altered in normal subjects, in patients with asthma, and in patients with pulmonary emphysema by the administration of bronchodilator agents without any evidence of an increase in lung elastic pressure. Therefore the relation of airway resistance to lung volume is conditioned by the distensibility of the lung tissue and of the airway walls, and the correction of airway resistance measurements for lung volume changes is not possible if these factors are not considered.

In the present series, the fall in airway resistance after the administration of norepinephrine and isoprenaline was not dependent on changes in the thoracic gas volume, since this variable did not increase. Thus it may be postulated that the decrease in the airway resistance was occasioned by an active increase of the bronchial lumen due to the action of the drugs.

The results of this study indicate that norepinephrine is an efficient bronchodilator agent. Its effects are probably due to its vasoconstrictive properties, which can diminish the mucosal congestion component of bronchial obstruction. In the doses used, norepinephrine did not elicit a further increase of the bronchial lumen when administered after isoprenaline. Moreover, isoprenaline caused an additional fall of the airway resistance when given after norepinephrine. Since the average results for airway resistance and thoracic gas volume were about the same after the cumulative use of both drugs (Table I), whatever the order of their administration, it can be concluded that the limit of drop of airway resistance was determined by isoprenaline. A possible explanation for this observation could be the stretching of the mucosa occasioned by the muscular relaxation and consequent bronchial: 
dilatation induced by isoprenaline, which would minimize the importance of the component of mucosal congestion.

\section{SUMMARY}

Twenty patients with long-standing bronchial obstruction were exposed to aerosols of norepinephrine and isoprenaline, used in alternate sequence. Both drugs elicited a significant decrease of the airway resistance. The results for airway resistance obtained when norepinephrine was administered after isoprenaline were not significantly different from those obtained with isoprenaline alone. Isoprenaline caused an additional fall of the airway resistance when given after norepinephrine.

\section{REFERENCES}

Briscoe, W. A., and DuBois, A. B. (1958). The relationship between airway resistance, airway conductance and lung volume in subjects of different age and body size. J. clin. Invest., 37, 1279.

Butler, J., Caro, C. G., Alcala, R., and DuBois, A. B. (1960). Physiological factors affecting airway resistance in normal subjects and in patients with obstructive respiratory disease. Ibid., 39, 584.

Ciba Guest Symposium (1959). Terminology, definitions, and classification of chronic pulmonary emphysema and related conditions. Thorax, 14, 286.

Cohen, A. A., and Hale, F. C. (1965). Comparative effects of isoproterenol aerosols on airway resistance in obstructive pulmonary diseases. Amer. J. med. Sci., 249, 309.

Cohen, B. M. (1962). Ventilatory responses to aerosols of isoproterenol and isoproterenol-phenylephrine. Curr. ther. Res., 4, 601.

DuBois, A. B., Botelho, S. Y., and Comroe, J. H., Jr. (1956). A new method for measuring airway resistance in man using a body plethysmograph: values in normal subjects and in patients with respiratory disease. J. clin. Invest., $35,327$.

Kallós, P., and Kallós-Deffner, L. (1964). Comparison of the protective effect of isoproterenol with isoproterenol-phenylephrine aerosols in asthmatics. Int. Arch. Allergy, 24, 17.

Simon, G., and Galbraith, H. J. B. (1953). Radiology of chronic bronchitis. Lancet, 2, 850 . 